\title{
An Outlook for Chemistry in Chile in 2000
}

This article was contributed by Prof. Eduardo J. Delgado (Department of Physical Chemistry, Faculty of Chemical Sciences, Casilla 160-C, Universidad de Concepción, Concepción, Chile; E-mail: edelgado@udec.cl), Secretary of the Chilean Chemical Society.

\section{Summary}

This article surveys the history of chemistry in Chile as well as the current general aspects of research, human resources, graduate programs, and the main features of the Chilean Chemical Society.

\section{History}

Science, in general, was not important during the colonial period in Chile. Chemistry, in particular, underwent little development, with its activity limited to sporadic analyses of water and minerals. Teaching of chemistry on a regular basis, as well as some rudimentary research, began with the arrival of the Polish scientist Ignacio Domeyko, who was hired by the Chilean government to teach chemistry and mineralogy. In 1838, Domeyko founded the first laboratory of chemical analysis at the Colegio de Coquimbo. Domeyko was aware that science was the basis for economic development, and he, therefore, stressed the theoretical and practical study of chemistry and physics. In his laboratory, he trained the first Chilean chemists, who later became the chemistry teachers of the next generations.

As the $19^{\text {th }}$ century was drawing to a close, the Chilean government hired German scientists to teach and develop the basic sciences in the country. However, by that time chemistry was regarded solely as an ancillary discipline in the study of other specialties, such as engineering, medicine, or pharmacy. As recently as the early part of the $20^{\text {th }}$ century, the situation had not changed appreciably; chemistry was still limited to a secondary role within the academic environment.

In the 1940s, even though a state policy for science was yet to be defined, the chemical community began to organize in small groups, mainly within the universities [1]. Thus in 1944 , on the $25^{\text {th }}$ anniversary of the Universidad de Concepción, the First Chilean Congress of Chemistry was held. At this congress, the bases for the future foundation of the Chilean Chemical Society were laid down, and the Society was officially established on 12 December 1946. The first issue of the Society's journal, the Boletin de la Sociedad Chilena de Química, ap-

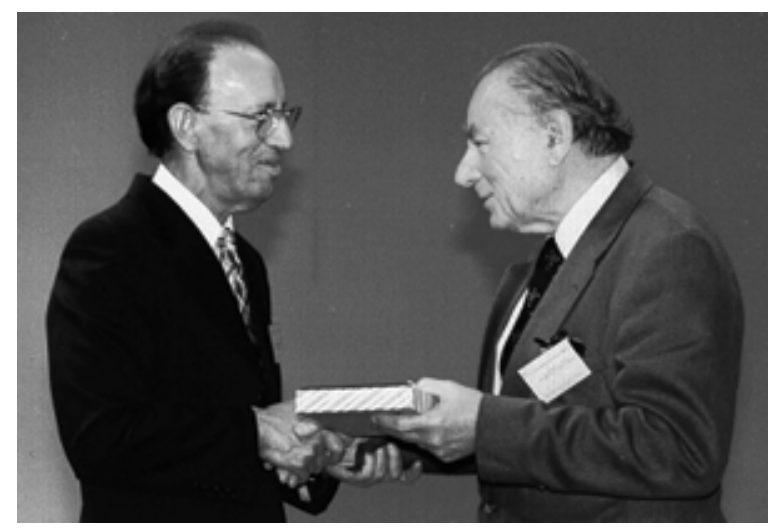

Prof. Ernest Eliel (right), on the occasion of his nomination as an Honorary Member of the Chilean Chemical Society, receiving the award from Prof. Guillermo Contreras, President of the Society, at the 23 $^{\text {rd }}$ Chilean National Meeting held in Valdivia, 24-27 November 1999.

peared in March 1950. In 1967, the National Commission for Scientific and Technological Research (CONICYT) was created with three goals: (1) to promote and fund scientific research, (2) to establish graduate programs at the universities, and (3) to devise national policies for scientific development. A remarkable impetus for scientific research grew with the establishment of graduate programs in the 1970s.

\section{Research}

According to figures from the Institute for Scientific Information (ISI) [2], the Philadelphia-based institute that monitors scientific publishing trends, Chile produces more international papers per capita than Argentina and three times as many as Brazil and Mexico. The Chilean government spends about $0.67 \%$ of gross domestic product (GDP) on research-more than any other country in the regionyet far below developed countries such as the United States, Japan, or European countries that spend over $2 \%$ of GDP. As in most developing countries, the Chilean budget for research and development has been subject to large fluctuations throughout the country's history. Such budget variations denote the lack of a stable policy for science and technology in Chile, unlike the situation in more developed countries where a fairly stable budget is observed over time. This fact reveals that research, historically, has not been considered an important activity for the country. 
The Chilean government supports peer-reviewed research through its National Commission for Scientific and Technological Research (CONICYT) [3]. CONICYT spends most of its budget on two funding programs: (1) the National Fund for Scientific and Technological Development (FONDECYT), which supports roughly 1000 basic research projects for up to three years, and (2) the Fund for Fostering Scientific and Technological Development (FONDEF), which spends a roughly equal amount on projects with potential economic impact in priority areas such as mining, forestry, and agriculture. The government's participation in funding research has dropped since 1965 when it supported nearly $99 \%$ of research to a level of about $70 \%$ in 1997 , mainly as a consequence of greater funding from industry. It is noteworthy that during this period, actual cash support of research by the government has increased; its lower percentage weight results from the appearance of alternative funding sources.

About $50 \%$ of the Chilean research budget goes to research universities, $25 \%$ is distributed through-

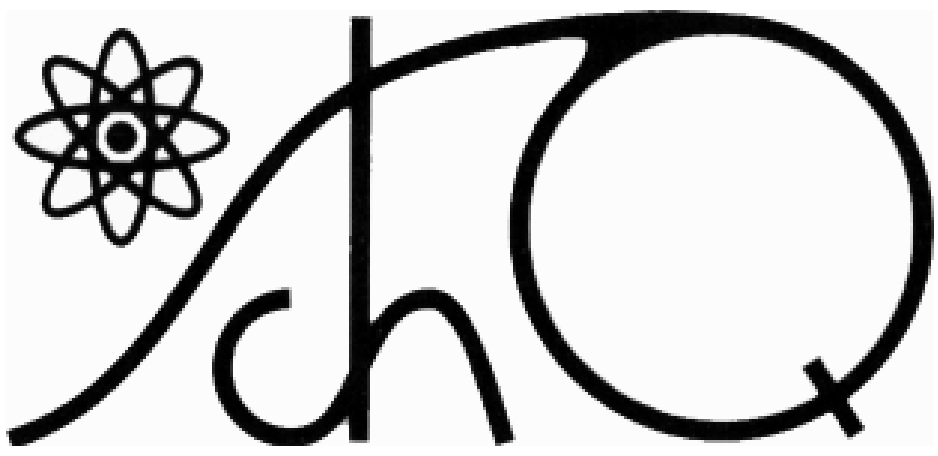

Logo of the Chilean Chemical Society (SChQ) number of articles published by Chilean authors in ISI-indexed journals has risen from 675 in 1981 to 1489 in 1996-an increase that doubtless can be attributed to the FONDECYT program. In chemistry, these figures increased from about 50 in 1981 to about 200 at present, with an average relative impact factor for the period of nearly 0.5. Relative impact factor is a comparison parameter that measures the frequency of citations to scientific articles; the world average is set at 1.0 [4].

\section{Human Resources}

Financial support and human resources are the bases for scientific and technological development. It is internationally accepted that the number of scientists and engineers is an important parameter to measure the status of science and technology. In Chile, the number of researchers, scientists, and engineers is low whether it is expressed as an absolute number or as a fraction of the total population. Chile has about 1.2 scientific professionals per thousand inhabitants in contrast to developed countries, where this number varies between 4 out the country, and the rest is shared among government institutes and other institutions engaged in research. Government support accounts for nearly $95 \%$ of the funds devoted to research in the universities. Currently, around $95 \%$ of the R\&D budget is devoted to basic and applied research; therefore, technological development is almost nonexistent. Since the establishment of FONDECYT in 1982, almost 7\% of the total funds disbursed have been spent on chemistry research projects totaling 4500 million pesos over the period 1982-1997.

One of the most important indices of R\&D is productivity, namely, the number of original articles published in international journals. Although Latin American papers account for only about $1.8 \%$ of the total number of articles in the journals indexed by ISI, an analysis performed for Science [1] by ISI shows that since 1981 the Latin American share has risen substantially, from about $1.3 \%$ to the current level-an increase of $38.5 \%$. Four countries-Brazil, Argentina, Mexico, and Chile-account for about 85\% of the Latin American papers; the Chilean contribution to the Latin American total is $12 \%$. The and 9 per thousand. Most of these researchers, scientists, and engineers are in universities (about $70 \%$ ), and the remainder are distributed in institutes (nearly 20\%), and industry (10\%). The total number of scientific professionals working in Chilean universities is about 4400 , with nearly 400 of them devoted to chemical research.

\section{Graduate Programs}

Chile has five graduate programs [5] leading to a doctorate in chemistry; they are located at the Universidad de Chile (initiated in 1973), Pontificia Universidad Católica de Chile (1973), Universidad de Concepción (1975), Universidad de Santiago (1983), and Universidad Católica de Valparaíso (1983). These programs have similar admission requirements, which include the degree of Licenciado en Química or equivalent, two letters of recommendation, and an interview. To complete a doctoral program successfully, a student must pass $6-8$ courses, a qualification examination in English, and a thesis presentation. The most important activity is the thesis, which must be an important and original contri- 
bution to the development of an area of chemistry. The time required to complete the thesis varies between two and four years. Currently, all five Chilean doctoral programs are accredited by CONICYT, and financial support, via fellowships, comes from CONICYT, the Ministry of Education through the Improvement of High Teaching Quality Program (MECESUP), Fundación Andes, and the universities.

Since 1968, about 150 young Chilean scientists have received doctoral degrees in chemistry. Most of them have taken academic jobs; fewer than $20 \%$ have gone to industry.

\section{The Chilean Chemical Society (SChQ)}

The Chilean Chemical Society (SChQ) was founded in 1946 to promote all areas of chemistry, as well as to advise educational and government authorities. The society is organized by Regions (Regionales) and Divisions (Divisiones). Regions are centers that comprise members within a single city; the five Regions are based in La Serena, Valparaíso, Santiago, Concepción, and Valdivia. Divisions, as in other chemical societies, group people with interests in a particular branch of chemistry. Each Division organizes periodic meetings, seminars, and workshops. The Divisions currently include Catalysis and Adsorption, Macromolecules, Chemical Education, Natural Products, Inorganic Chemistry, Analytical Chemistry, and Environmental Chemistry. Each Region and Division has its own President and Council, elected by its members. Membership for both is open to all chemists in the Society, which now has about 400 members.

The SChQ organizes and supports a broad range of activities to enhance public awareness and promote a positive image of chemistry through a strong program of public lectures, public symposia, exhibitions, posters, and booklets. Every year, the Chemical Education Division organizes the Olimpiadas de Química (Chemistry Contests) aimed at enhancing interest in chemistry among high school students. Students from all over the country participate in this event. The winners later compete in the Olimpiadas Iberoamericanas de Química (Iberoamerican Contests), which are held in a different Iberoamerican country each year.

The national meeting of the Society is the Jornadas Chilenas de Química, which takes place every two years and includes academic and industrial chemists from all over the country. Graduate students play an important role at these meetings, where they have the opportunity to report and discuss their research results with the national chemical community.

The Society publishes the Boletin de la Sociedad Chilena de Química, which is a quarterly journal reporting original research in all areas of chemistry. Its first volume was published in March 1950, and its current volume is No. 45, whose first number was published in March 2000. The Boletín is indexed in Current Contents and the Science Citation Index, and it is currently one of the Iberoamerican journals with a high relative impact factor-quite an accomplishment for a Society as small as the SChQ. The Boletin is sent to all members of the Society. Currently, the SChQ web site is at http://www.schq.cl.

At present, the Chilean Chemical Society participates actively in several international scientific organizations, including the International Council for Science (ICSU), Federación Latinoamericana de Asociaciones Químicas (FLAQ), Pacific Basin Societies (PBS), and IUPAC. The SChQ maintains permanent exchange programs with the American Chemical Society (ACS), as well.

\section{Closing Remarks}

The most important goals of the SChQ are to enhance awareness of the importance of science in general and of chemistry in particular in everyday life. This message must be brought home at three different levels. First, and most important, it must reach the younger generation of Chileans, represented by prehigh school students. Second, government authorities must also be included in the scheme. Finally, the public at large needs to accept the inherent need for and benefit of science in the contemporary world. The general population also needs to consider large numbers of scientists and institutions doing research as a reason for national pride and not as a bothersome liability.

Many problems and obstacles remain, but the achievement of the national chemical community in the last 50 years leads us to regard the future of chemistry in Chile with sound optimism.

\section{References}

1. T. González Abuter. Sociedad Chilena de Química 50 Años al Servicio de la Ciencia, 1946-1996. Sociedad Chilena de Química (1996).

2. C. Macilwain. Nature, Supplement to Vol. 398, No. 6726, 1 April 1999.

3. Indicadores Científicos y Tecnológicos, Enrique Dellacasa (Ed.), CONICYT (1998).

4. Science in Latin America in Science 267, 808-827 (1995).

5. Programas de Postgrado en Química de las Universidades Chilenas, Guillermo González (Ed.), Sociedad Chilena de Química (1994). 